\title{
Recovery Improvement of Fine Iron Ore Particles by Multi Gravity Separation
}

\author{
Subrata Roy*
}

MNP Division, National Metallurgical Laboratory, Jamshedpur 831 007, India

\begin{abstract}
Conventional gravity separation process of iron mineral fines is not very effective. In present work Multi Gravity Separation (MGS) process has been studied. This study was performed on a low-grade iron ore namely goethiticlateritic ore (GLO) from Eastern India. Detailed mineralogical, physical and chemical characteristics of a goethiticlateritic iron ore showed that the sample contained porous and friable oxides and hydroxides of iron. The ore sample had a feed grade of $54.43 \%$ total $\mathrm{Fe}, 9.27 \% \mathrm{SiO}_{2}$ and $8.02 \% \mathrm{Al}_{2} \mathrm{O}_{3}$. Hematite and goethite are main iron-bearing minerals while kaolinite and gibbsite are the major gangue mineral constituents. Considering the characterization data, these ores were ground separately to three size fractions, namely $-300 \mu \mathrm{m},-250 \mu \mathrm{m}$ and $-150 \mu \mathrm{m}$ sizes and subjected to flowing film concentration in Wilfley Table. As revealed by the liberation study, higher concentration was obtained by the processing of $-150 \mu \mathrm{m}$ crushed sample. The grade of the ore was improved from $54.43 \% \mathrm{Fe}$ to $65.71 \% \mathrm{Fe}$. However, significant amount of fine iron ore particles were lost during the processing of $-150 \mu \mathrm{m}$ size ore, because it is not very effective for particles less than $15 \mu \mathrm{m}$. Thus, fine hematite and goethite particles are usually not recovered resulting in the loss of valuable iron ore fines. To recover this fine, Multi Gravity Separator was used in place of Wilfley Table and was found to be effective in reducing loss of fine iron particles and increasing the grade of the concentrate. The MGS process improved the $\mathrm{Fe}$ from $54.43 \%$ to $66.5 \%$ along with decreasing the alumina from $8.02 \%$ to $1.17 \%$.
\end{abstract}

Key Words: Comminution, fine particle processing, multi gravity separator, gravity concentration, grinding, liberation.

\section{INTRODUCTION}

Important iron ore deposits occur in India in the eastern, central and southern parts in the states of Jharkhand, Orissa, Karnataka, Chhattisgarh, Goa, etc. Geologically, the Eastern Indian iron ores belong to Archean Iron Ore Group (IOG). Indian iron ore is relatively rich in $\mathrm{Fe}$ and contains higher amounts of alumina compared to the other major deposits of the world. With increasing global demand of iron ore owing to the huge requirement of iron ore by China, important iron ore producing countries have increased their production by initiating steps to utilize the low grade iron ores, fines and slimes.

The constraints in the beneficiation of iron ore falls in two classes. First problem is the classic issue of upgrading Indian iron ores which are relatively high in alumina and silica as desired by the blast furnace route. The second problem is the utilization of huge amounts of iron ore fines and slimes which are not only a loss of the very important iron ore resource, but also pose severe long term environmental problems $[1,2]$. The issue of the utilization of iron ore slimes, however, is fairly complex owing to the extremely small size of the individual mineral particles and has not met with great success until now. However, many of the other issues related to mineralogical characterization, physical liberation and mineral dissemination are common to both these kinds of problems. Enrichment of low grade iron

*Address correspondence to this author at the MNP Division, National Metallurgical Laboratory, Jamshedpur 831 007, India;

Email: roy.subrata11@yahoo.com ores always involves comminution for mineral liberation and significant amount of ultra-fines are generated during this process and these ultra-fines are difficult to concentrate.

Main difficulty in processing and utilization of low grade iron ores primarily stems from their compositional characteristics as well as the soft nature of some of the ores and their typically high alumina content [3]. The composition of the Indian iron ores is typified by high iron content with relatively higher amount of alumina (as high as $10 \%$ to $15 \%$ ) [3]. The high alumina and silica pose serious operational problems during sintering and subsequent smelting in blast furnace. High alumina in iron ore and sinter leads to viscous slag formation during smelting, that in turn requires a high coke rate [4]. There is a vast scope of this work in India as the alumina affects the quality of blast furnace burden in a variety of ways. It has adverse role on sinter strength and degrades reduction properties. It causes enhanced slag volume, viscous slag formation, decrease in productivity, increase in fuel rates in the blast furnace and higher energy consumption. Thus removal of alumina and other deleterious elements from iron ores leads to better sinter product with higher reducibility, lesser slag formation and fuel consumption, better slag separation which ultimately lead to higher cost efficiency, higher blast furnace productivity and better quality of steel. Thus, beneficiating the low grade iron ore to remove the gangue minerals and enhancing its grade is a prospective proposition today.

\section{REVIEW OF THE MINERAL PROCESSING TECHNOLOGY}

Earlier efforts have been made to reduce alumina in the slime using classification followed by separation in a 
hydrocyclone [5]. They showed that it is possible to obtain a product containing $64 \% \mathrm{Fe}, 1.4 \%$ Silica and $3.5 \%$ Alumina from a feed assaying $57 \% \mathrm{Fe}, 4 \%$ Silica and $8.3 \%$ Alumina. Several researchers have worked on alumina reduction focusing on flocculation techniques that met with variable degrees of success [6-8].

Beneficiation of iron ore slime produced from washing plants and tailing ponds of Kiriburu mines was studied [9] using wet high intensity magnetic separators followed by classification in hydrocyclone. It was shown that a concentrate assaying $63 \% \mathrm{Fe}$ and $3.3 \%$ alumina could be produced with an overall iron recovery of $56 \%$. Multi-gravity separation is a useful technique for treating iron ore slime and it is particularly effective for reducing alumina [10].

Separation of Barsua, Bolani and Kiriburu iron ore slimes was studied [11] using classification by hydrocyclone followed by high intensity magnetic separation. Their results show that it is possible to obtain a concentrate assaying $60-65 \% \mathrm{Fe}$ and with $60-80 \%$ recovery. Another study [12] used classification in hydrocyclone followed by spiral concentration for iron ore slime obtained from washing plants and tailing ponds of Kiriburu mines. The experimental results show that it is possible to raise the iron content up to $64.17 \%$ at a yield of $37.3 \%$ with simultaneous decrease in the alumina content to $1.17 \%$.

The most commonly used beneficiation methods for iron ores are the gravity methods. Recovery of valuables from natural ores by gravity concentration process is one of the oldest techniques [13]. While, in the twentieth century gravity concentration has been partially replaced by other processes, notably flotation and magnetic separation, they have not made it obsolete. Gravity separation technique is widely used in mineral beneficiation practices for its low cost, ease of operation, and eco-friendly nature. Differential settling velocity of particle is the basis of such processes. The settling velocity of particle is governed jointly by weight, buoyancy and drag force. The most commonly used gravity methods for beneficiation of iron ores are shaking table, jig [14] and spiral methods. Upgrading of iron ore by jigging has been an emerging trend [15]. Flowing film gravity concentration using Wilfley Table is a powerful technique for the recovery of fine iron minerals. Many theoretical and experimental investigations of Wilfley table have been reported [16-20]. Tabling efficiency is quite high when the specific gravity difference between the valuable and gangue minerals is high [21]. In addition, magnetic separation may be preferred, depending on the ore characteristics [22-25]. Floc-magnetic separation process is also reported for the processing of fines [26, 27]. Flotation is also used for the beneficiation of finely grained ores [28, 29].

With these conventional methods and depending on the liberation particle size of the ore, significant amounts of fine iron are lost to the tailings [30]. For this reason, all of these methods are only partly successful in the fine particle size range. However, significant advancement is made in the field of gravity separation by introducing several advanced gravity separators. In some of these techniques centrifugal field is applied to enhance the gravity. Separator, where centrifugal field is employed, are called enhance gravity separator (EGS) [31]. In certain instances, autogenous heavy medium is created when they are called teeter bed separator
(TBS) [32]. The EGS and TBS are capable of concentrating fines and ultrafines particles [33].

The Multi Gravity Separator (MGS) is able to separate two minerals from each other. The MGS is suitable for the treatment of fines with a maximum particle size of approximately $0.5 \mathrm{~mm}$. It is reported in literature that Multi Gravity Separator (MGS) has the potential to treat minerals fines and ultrafines like tin, chromium, iron and other ore minerals [34-36]. Recovering fine chromite from the gravity tailings of four different chromite concentrators of Turkey is investigated using a laboratory/pilot scale Mozley multigravity separator (MGS) [37].

Earlier work with iron ore and iron ore fine/slime indicates that beneficiation of iron ore and fine/slime containing very low iron and high alumina and silica is quite difficult. Also, it is equally difficult to know the characteristic properties of the particles where most of the population is below 50 micron. A detailed initial characterization of the particles is required before developing a suitable beneficiation flow sheet. The selection of beneficiation process is vastly dependent on the variation in physical, chemical and mineralogical properties between constituent minerals and their grain sizes. Therefore, the mineralogical characteristics of the samples form the basis of choosing an appropriate beneficiation process for up-gradation. Ore characterization relates to physical, chemical and mineralogical properties of raw materials to their behavior during their processing such as comminution, physical beneficiation as well as their hydrometallurgical processing [38]. In the present study a low grade iron ore sample was collected for detail characterization and beneficiation. The efficacy of gravity separation by Wilfley table is studied with a view to value addition of the ore. The effects of feed size and nature of the ore were studied simultaneously. When particle size was very small, the possibility of beneficiation of the ore was investigated using a MGS. The effects of drum rotation, wash water and angle of drum inclination were studied for grade and recovery.

\section{MULTI GRAVITY SEPARATOR}

The Multi Gravity Separator (MGS) is reported to be a promising equipment for the separation of particles in fine size range. The MGS is suitable for the treatment of fines with a maximum particle size of approximately $0.5 \mathrm{~mm}$. Maximum concentrate grade and maximum recovery is of today's demand with MGS concentration as it is with many concentration processes [39]. The equipment is based on a concept developed by M/s Richard Mozley Limited, U.K. [40]. The principle of MGS may be visualized by rolling the horizontal surface of a conventional shaking table into a drum and rotating the same along the horizontal axis. This causes application of an enhanced gravitational force, many fold higher than the normal one, on the mineral particle flowing across the surface. This leads to improvement in the treatment of fine particles in comparison to conventional separator like shaking table.

The schematic diagram of MGS is shown in Fig. (1). This basically consists of a slightly tapered open ended $0.6 \mathrm{~m}$ long drum with a diameter of $0.5 \mathrm{~m}$. The drum rotates in clockwise direction with a variable speed between 140 and 
a

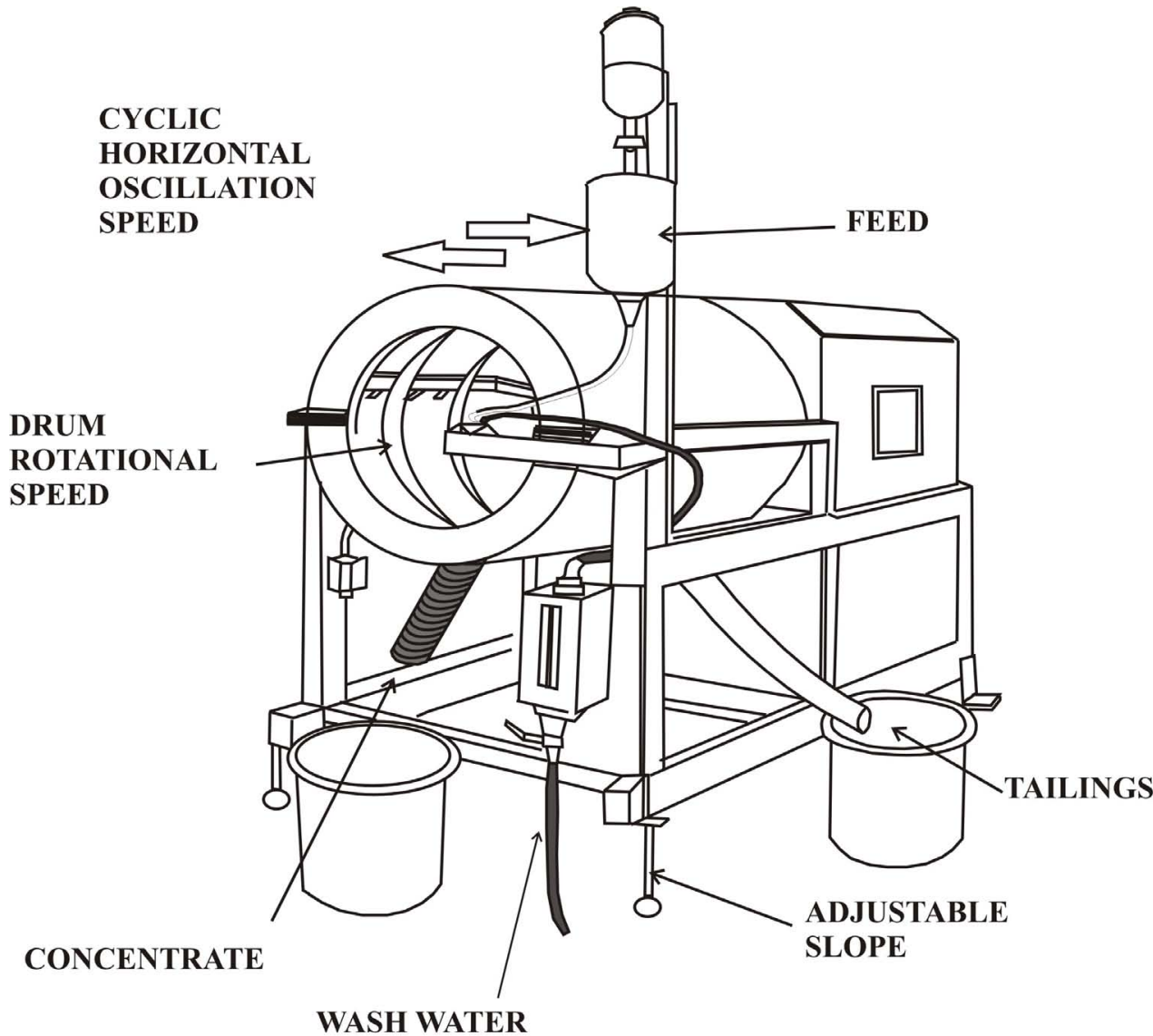

b

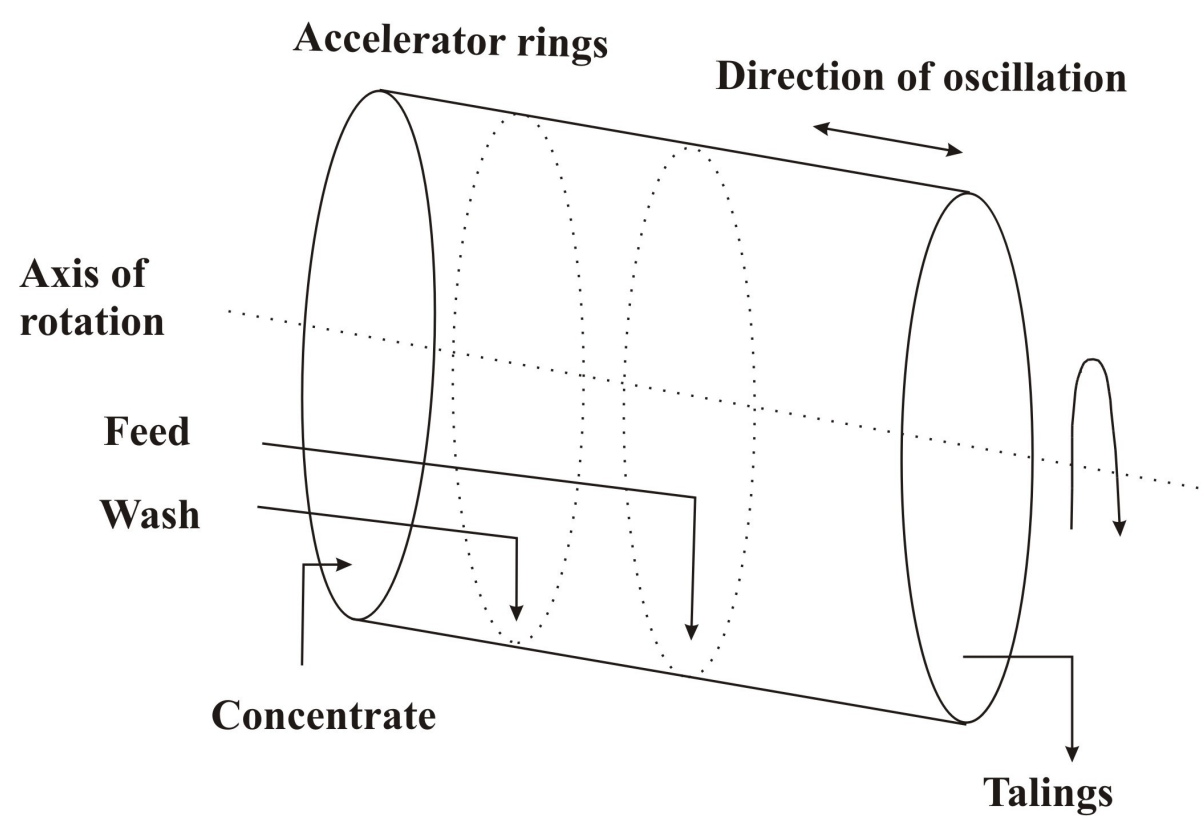

Fig. (1). (a). Schematic of MGS (b) Drum of MGS shows separation mechanism.

$300 \mathrm{rev} / \mathrm{min}$ leading to generation of a gravitational pull between 6 to 24 'g' on the drum surface [41]. A sinusoidal shake with amplitude varying between $12 \mathrm{~mm}$ to $25 \mathrm{~mm}$ is superimposed upon the motion of the drum in an axial direction. The shake frequency ranges between 2 to $6 \mathrm{cps}$. The drum is provided with a scraper assembly which also rotates in the clockwise direction but at a slightly faster speed. The important variables affecting the separation of minerals using MGS are the rotational speed of the drum, the shaking intensity, the wash water flow rate, the angle of tilt and the flow rate and pulp density of the feed.

Feed slurry is introduced continuously at the mid point on the internal surface of the drum through a mesh ring so as to reduce the turbulence due to entry effect (Fig. 1b). 
Wash water is added near the open end through a similar type of mesh ring. Flowing film forms on the internal surface of the drum. Studies signify that the slurry follows a spiraling pattern on the revolving drum surface. Heavier particles or particles of higher specific gravity penetrate the slurry and are pinned to the surface of the drum as a result of the centrifugal forces to form a semi-solid base layer. An intermediate layer forms above this consisting of a relatively dilute suspension of lower specific gravity particles, and slime particles. The top layer consists of relatively clear water. The shake provides an additional shearing force on the particles in the flowing film, resulting in improved separation, whilst the specially design scrapers moving across the drum surface continually re-grade the settled particles, thus minimizing the entrainment of gangue.

Thus the high density particles pinned to the surface of the drum are continuously swept up the slope by the scarapers, during which time they are subjected to counter current washing before discharging at the open, front end as concentrate. The lower density minerals along with the majority of wash water flow down-stream to discharge as tailing via slots at the inner end of each drum.

\section{MATERIALS AND METHOD}

A very low grade iron ore sample, namely goethiticlateritic iron ore was collected for the investigation. The sample belongs to Jilling-langalata iron ore deposits of Eastern India. The iron ore sample contained $54.43 \%$ total $\mathrm{Fe}, 9.27 \% \mathrm{SiO}_{2}$ and $8.02 \% \mathrm{Al}_{2} \mathrm{O}_{3}$.

The ore samples are cut to small sizes by a diamond wheel saw (Carl Zeiss) and Isocut slow speed saw (Buhler make) and samples were prepared to study under reflected light microscopes. For ore microscopic study, the samples were polished by conventional polishing techniques, cleaned ultrasonically and examined under orthoplane microscope (Leitz make). The mineralogy texture, microstructure grain size distribution pattern and grain size, etc. in respect to various ore types were established by this study.

Micromorphological and mineralogical characterization studies were conducted using Scanning Electron Microscopy attached with EDS microanalyser (JSM 840 A / EDS). This study allowed the differentiation of various mineral phases, micromorphological features and textural features of the ore.

Image analysis of different size fractions of the iron ore sample was performed for liberation study. Washed iron ore was properly ground separately into different size fraction for liberation studies. Each of these size fractions were carefully mounted using bakelite powder in Simplimet mounting press. More than 50 images for each size class were processed for field measurement method after binary conversion for liberation study.

Through this method the volumetric percentages of interlocking of iron particles with gangue phases and percentage of gangue liberated in each size fraction was estimated. The volumetric grade distributions was transformed to the corresponding distribution weight by mass for computational simplicity. This was done by knowing the densities of mineral phases present in the ore [12]. The theoretical density of hematite and goethite are 5.5 to $6 \mathrm{~g} / \mathrm{cm}^{3}$ and $4.5 \mathrm{~g} / \mathrm{cm}$ respec- tively. However, porosity is present in ores, so an average value of $5.2 \mathrm{~g} / \mathrm{cm}^{3}$ for hematite and $4.2 \mathrm{~g} / \mathrm{cm}^{3}$ for goethite was assumed. The gangue, mainly kaolinite and gibbsite, was assumed to have a density equal to $2.6 \mathrm{~g} / \mathrm{cm}^{3}$.

Particle size measurements of the iron ore were done using Shimadzu SA-CP3 particle size analyzer. In order to collect samples in each size range, sieving of iron ore sample was carried out using the Vibratory Laboratory Sieve Shaker "Analysette3". For separation of -50 micron particles micro-precision sieves were used. Characterization was also performed using sink-float studies in heavy liquid to assess the distribution of iron particles in the form of sink. Pure bromoform (sp. gr. 2.81) was used to quantify the heavy (sp.gr. > 2.81) and light (sp.gr. < 2.81) fraction content of the sample.

Wilfley table separator termed as flowing film concentration has been used for effective gravity separation. This technique can be used to separate minerals, both on the basis of their shape as well as specific gravity. The equipment used for this study was of Carpco, USA make, with a deck size of $1.27 \times 0.61 \mathrm{~m}$. The unit was driven by a $440 \mathrm{~V}, 3$ phase motor. Experimental condition with $3^{\circ}$ deck slope, $1.68 \mathrm{~cm}^{3} / \mathrm{cm} / \mathrm{s}$ water flow rate and $10 \%$ pulp density was kept constant in all experiments.

To see the effect of advanced gravity separation of fine iron particles, Multi Gravity Separator which is an enhancement of the Wilfley table has been used. The operation of the Multi-Gravity Separator is controlled by Speed of rotation of drum, Inclination of the drum, Frequency and amplitude of the shake, Flow of wash water, Pulp density of feed and feed rate and other factors like scrapper width, scrapper speed and angle of lining also affect the performance of Multi Gravity Separator to some extent. While all the parameters mentioned above affect the performance to some extent, the principal variables considered were drum speed, wash water flow rate and inclination of Drum. The equipment used for this purpose was the MGS unit from BARTLES LTD, UK, Capacity 0.2 tone / hour (dry basis). Feed particle size range is 500 micron to 1 micron.

\section{CHARACTERIZATION}

The characterization of the iron ore sample consisted of their microscopic examinations, X-Ray diffraction study (XRD), Scanning Electron Microscopy (SEM) with Energy Dispersive Spectrometer (EDS), image analysis and size measurement. These steps are described in detail in the following sections and corresponding results are presented.

Goethitic-lateritic ore is dull earthy in color with limonitic red, yellow and dull white patches. However, in fresh surface, it appears darker in comparison to soft laminated ore. Goethitic-lateritic ore mainly contain goethite, hematite, kaolinite, gibbsite and quartz. Microplaty hematite, goethite with clay patches are common features in this type of ore. Goethite is present in all the samples. There are extensive features of cavity filling by goethite precipitation (Fig. 2a). These cavities are also partly filled by gibbsite and kaolinite. Spongy micro-platy hematite and martite, partly or wholly transformed to goethite and later concreted by goethitic precipitation along the wall of the tubular pores. At places, goethite occurs as colloform bands (Fig. 2b). This ore also 
exhibits multiple joint and fracture surfaces along which the clay and goethite precipitation takes place. Most of the sample shows high degree of porosity with substantial amounts of clay, which is mainly responsible for the high alumina content in this ore that makes it difficult for use in iron making without rigorous beneficiation. The clay bearing ore contain clusters of gibbsite grains in the voids and fine kaolinite needles in the nodules (Fig. 2c). Most of it is generally soft and friable and leads to slime generation during mining and handling [1-3].

XRD pattern also reveals that iron ore is mainly comprised of hematite and goethite (Fig. 3a). XRD analysis of
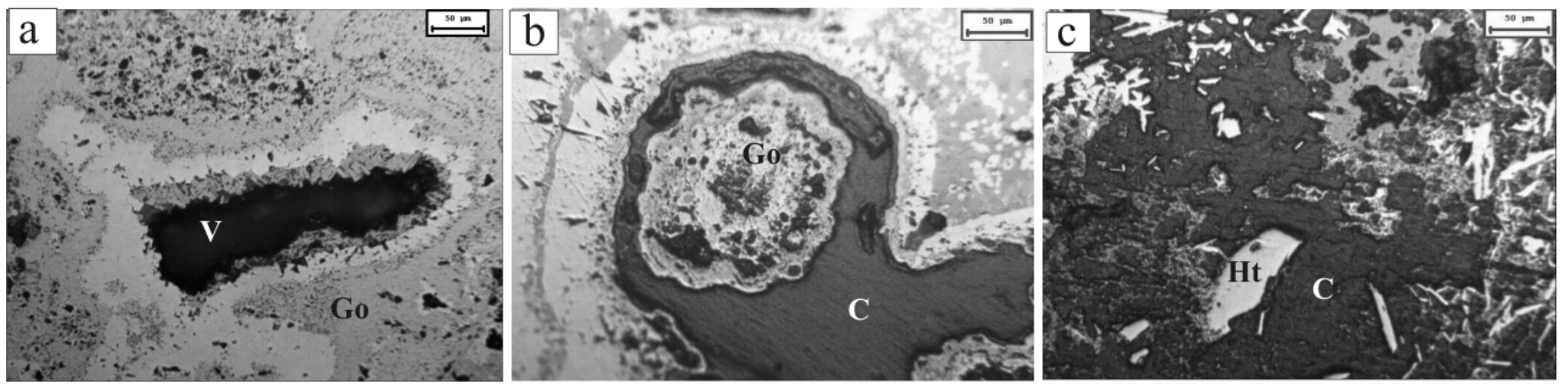

Fig. (2). Photomicrograph of goethitic lateritic iron ore. (a) cavity filling by goethite precipitation, b) colloform goethite, c) clusters of gibbsite grains in the voids and fine kaolinite needles in the nodules (Ht-hematite, Go-goethite, C-clay, V-voids).

a

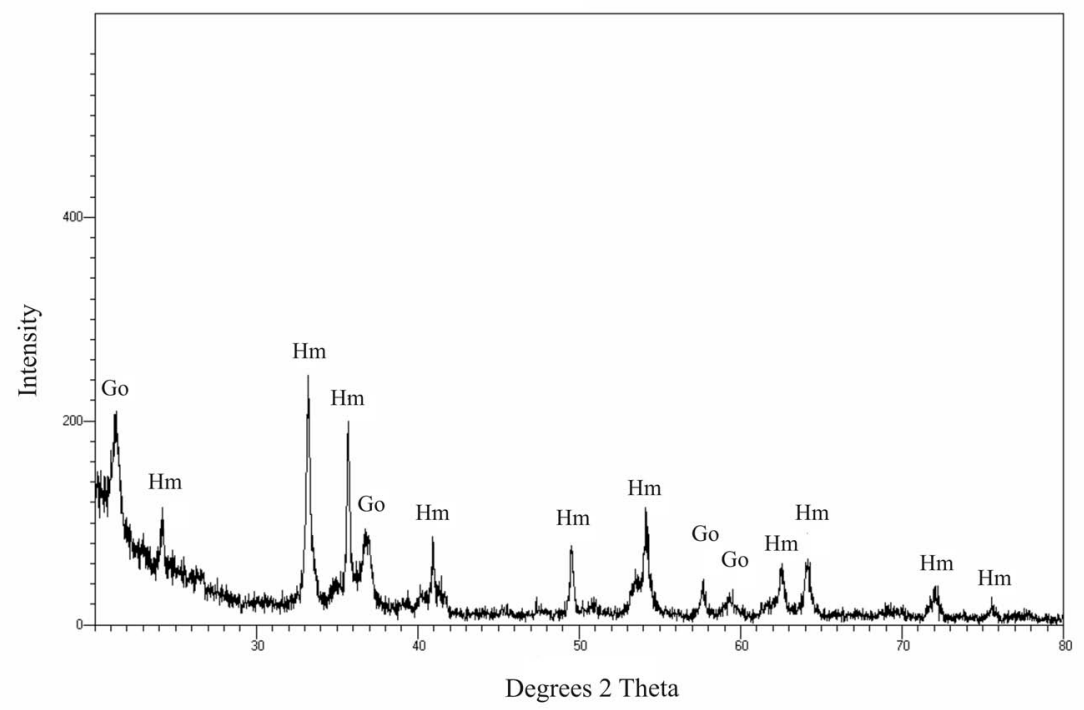

b

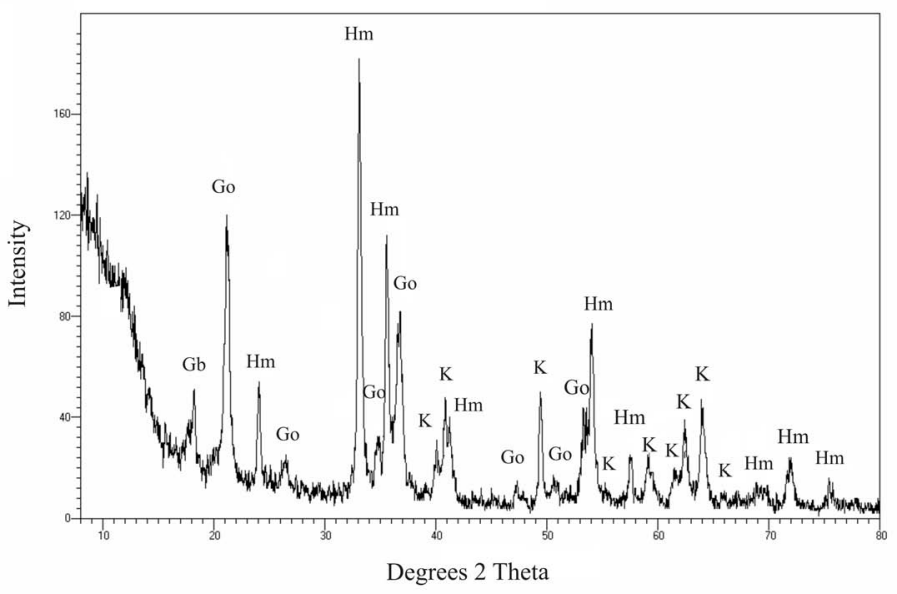

Fig. (3). XRD pattern of iron ore samples with identified phases. (a) Ore, (b) Gangue fraction (Hm-hematite, Go-goethite, K-kaolinite, Gb-gibbsite). 
the clay material shows that it is mainly composed of kaolinite and gibbsite as evident from Fig. (3b).

SEM observation of Goethitic-lateritic ore shows that goethite is the common mineral (Fig. 4). It is formed under oxidizing conditions as a weathering product of iron bearingminerals [42]. The goethite contains variable quantities of impurities as Al and Si (Fig. 4) which can be seen by EDS analysis (Go). These impurities are intricately associated with goethite and it is very difficult to remove it from the ore.

Liberation analysis (Fig. 5) of goethitic-lateritic ore shows that in coarser fractions percentage of interlocking is very high and decreased with decreasing particle size. Low

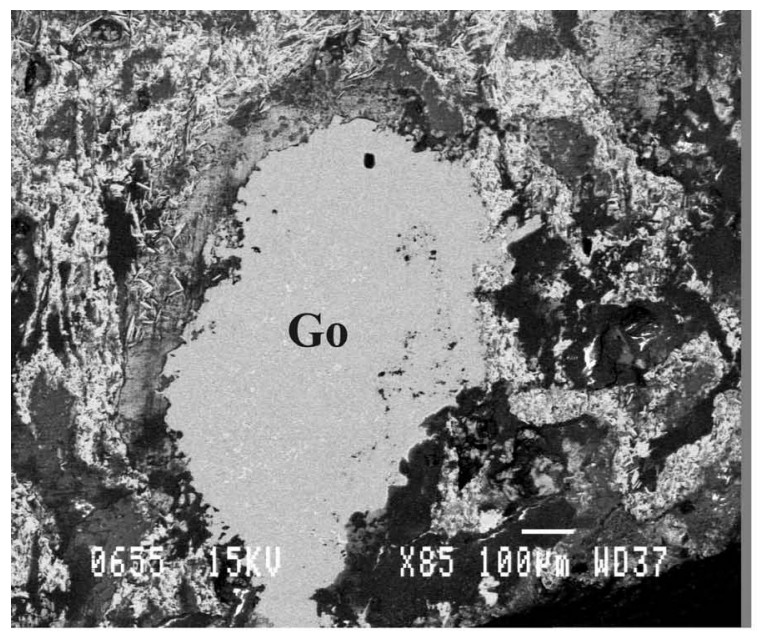

free hematite content and higher gangue contents indicate very low grade of this type of iron ore. Complex interlocking nature of the particles shows that the liberation can be achieved below $150 \mu \mathrm{m}$ size. Achieving high purity concentrate in beneficiation of this ore is likely to be quite difficult due to the complexity of interlocking. Proper comminution is required to break the interlocking and attain good liberation in this case.

Graphical representation of the size analysis data of the iron ore samples is shown in Fig. (6a). It is seen from the size measurement that goethitic-lateritic ore is very fine in nature. Substantial amount of the ores is below $150 \mu \mathrm{m}$ indicating significant slime generation during desliming. Graphical representation of the size wise chemical composi-

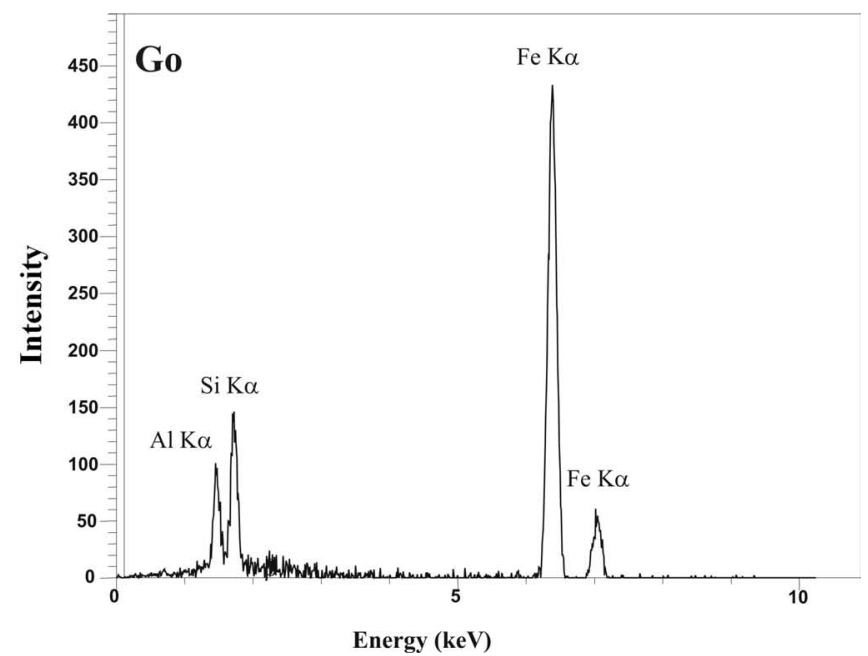

Fig. (4). SEM photomicrograph of goethite in GLO containing Al and Si. (Go-goethite, C-clay).

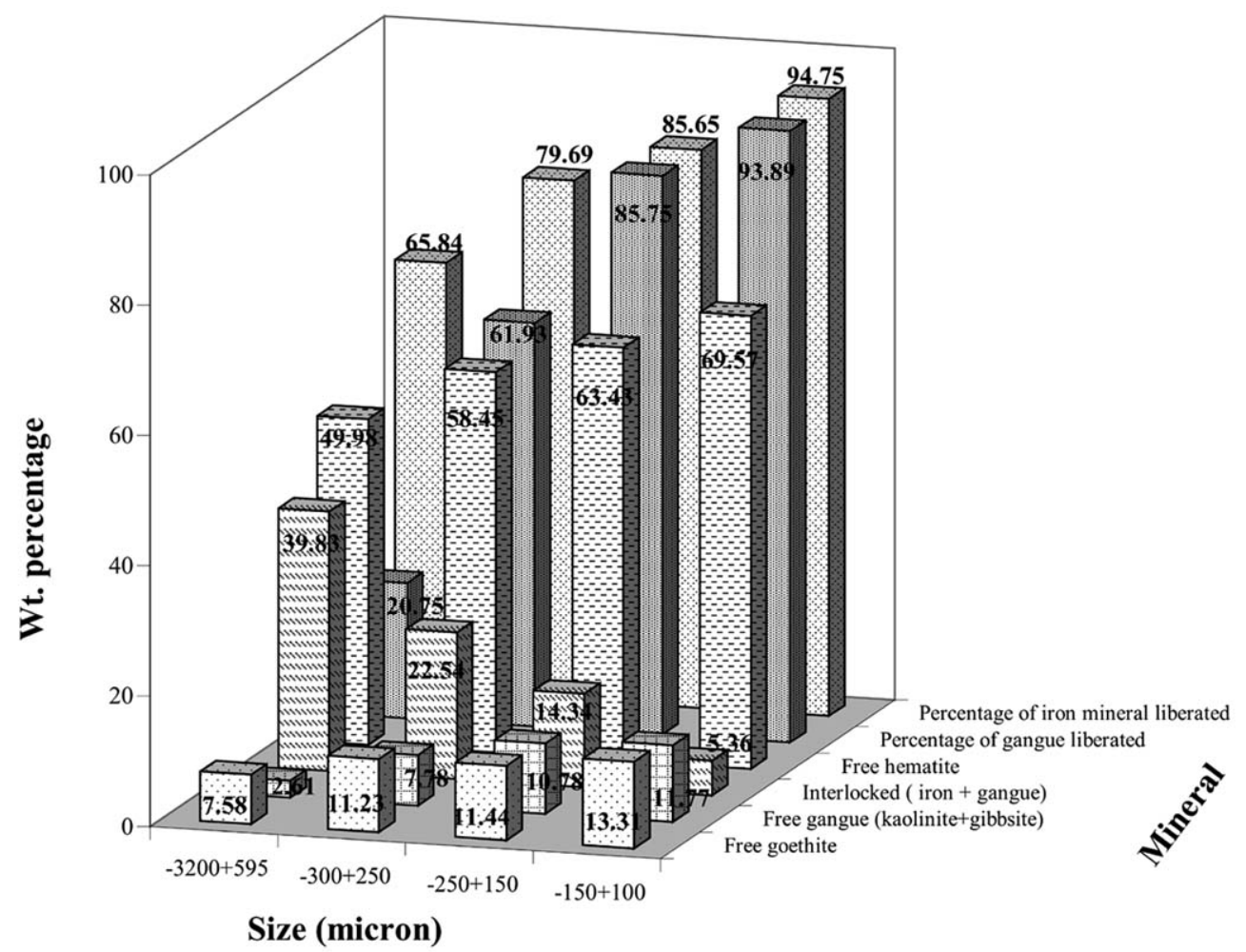

Fig. (5). Liberation pattern of goethitic-lateritic ore. 
tion of the iron ore sample is shown in Fig. (6b). The figure shows that iron is mainly concentrated in the coarser size fraction. Therefore, most of the gangue would be concentrated in lower sizes.

\section{BENEFICIATION STUDIES}

Detailed characterization of the iron ore revealed that most of the impurities in the form of alumina and silica are concentrated in the finer size fractions while iron is concentrated in the coarser size fractions. Therefore, it is reasonable to expect that removal of ultrafines using a desliming operation would improve the grade. A beneficiation scheme was chosen involving size classification in a hydrocyclone followed by gravity separation. To study the beneficiation prospects of coarse particles a first stage of gravity separation by Jigging is carried out. Finally, further comminution and a second stage of Tabling operation and/or Multi Gravity Separation is employed to generate sinter/pellet grade concentrate. The simple flowsheet of Fig. (7) was designed in order to utilize the differences in specific gravity between the valuable and gangue minerals.

Removal of ultrafines using a hydrocylone indicates that $\mathrm{Fe}$ values can be upgraded substantially by desliming operation, as shown in Table 1. Desliming improves the Fe $\%$ from $54.43 \%$ to $58.45 \%$ with reducing the alumina and silica content from $8.02 \%$ and $9.27 \%$ to $5.78 \%$ and $6.76 \%$ respectively.
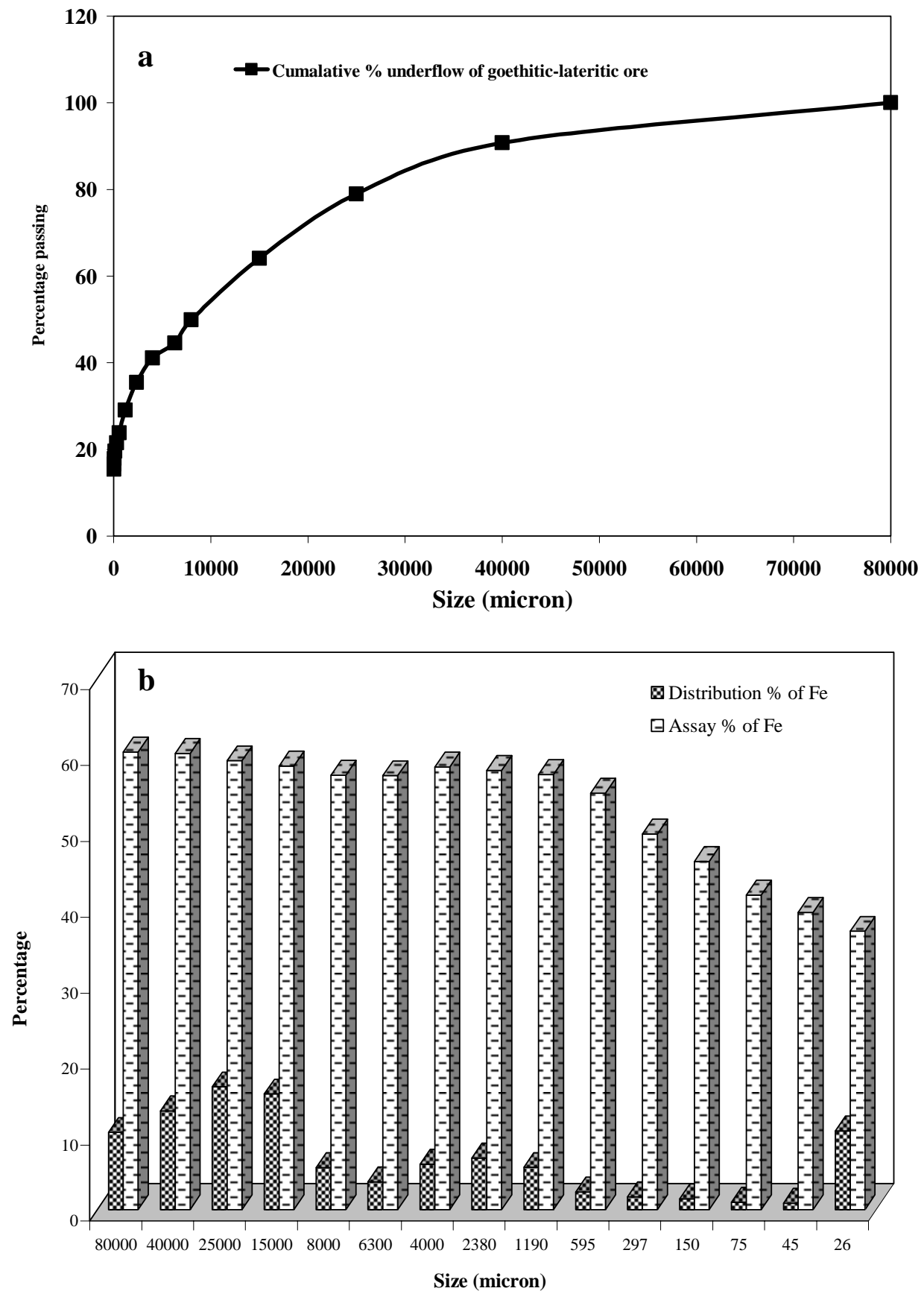

Fig. (6). Graphical representation of (a) particle size distribution, (b) Size wise chemical analysis. 


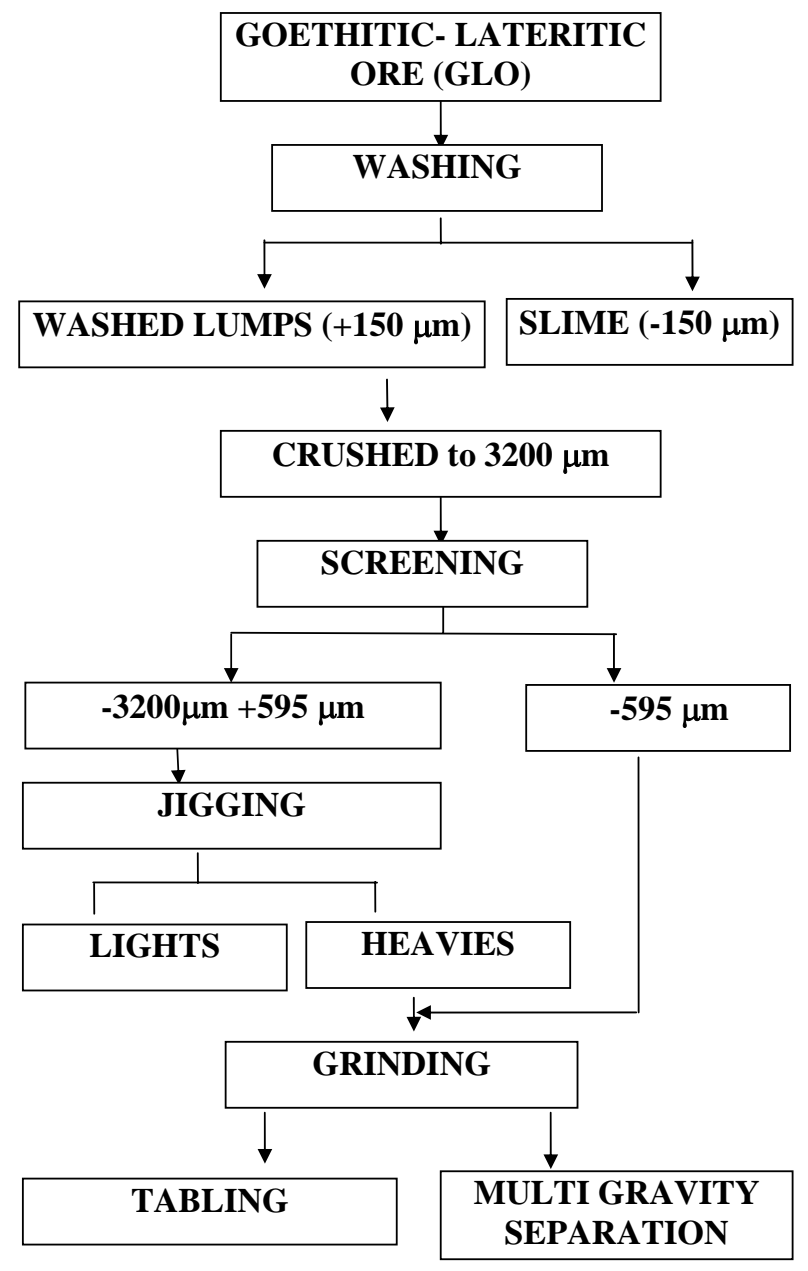

Fig. (7). Processing flowsheet.

The washed lumps, after desliming operation contains considerable amount of coarse ore pieces (> $3200 \mu \mathrm{m})$. They were crushed to $-3200 \mu \mathrm{m}$ size. The crushing operation generated significant amount of fines less than $595 \mu \mathrm{m}$ (Table 2). The $-3200+595 \mu \mathrm{m}$ size fraction contains $58.95 \%$ total Fe, $6.69 \%$ silica and $5.74 \%$ alumina. This size fraction was subjected to gravity separation by Jigging. Jigging result, as shown in Table $\mathbf{3}$, indicates that only small amount of gangue is rejected. The Fe\% has been increased to $61.12 \%$ with decreasing the alumina and silica content to $4.24 \%$ and $5.11 \%$ respectively. A combined product is prepared by combining the jigging concentrate with $-595 \mu \mathrm{m}$ size ore as shown in Table 4. It is observed that the resulting concentrate grade of the combined product is still not high enough to be acceptable feed material for pelletisation/sintering. The combined product contains $59.73 \%$ Fe with $4.85 \%$ alumina and $5.79 \%$ silica. Therefore, further concentration is required.

Liberation analysis of different ground size fraction of the iron ore suggests that grain size reduction to less than $300 \mu \mathrm{m}$ size is necessary to achieve sufficient liberation of iron ore minerals from the gangue (kaolinite and gibbsite). Therefore, the Jigging concentrate $(-3200+595 \mu \mathrm{m})$ and -595 $\mu \mathrm{m}$ material are subjected to further comminution. To investigate the optimum particle size requirement for adequate enrichment, the iron ore is ground separately to three different finenesses, i.e., $-300 \mu \mathrm{m},-250 \mu \mathrm{m}$ and $-150 \mu \mathrm{m}$. In order to study the efficacy of gravity concentration, these samples were subjected to concentration in Wilfley Table.

Experimental condition with $3^{\circ}$ deck slope, 1.68 $\mathrm{cm}^{3} / \mathrm{cm} / \mathrm{s}$ water flow rate was kept constant in all tabling experiments. The results obtained from the best tests are given in Table 5. It is observed that the quality of the ore improved significantly by tabling. However, slightly contrasting results are obtained for these two types of iron ores. Different concentration grade is obtained from the feed ground to different fineness. The concentrate grade improved to $63.76 \%, 64.12 \%, 65.71 \%$ Fe by processing the three feeds ground to $-300 \mu \mathrm{m},-250 \mu \mathrm{m}$ and $-150 \mu \mathrm{m}$, respectively.

Processing of $-150 \mu \mathrm{m}$ ground material shows that the grade of the ore is improved from $59.73 \% \mathrm{Fe}$ to $65.71 \% \mathrm{Fe}$ (Table 5). The silica and alumina content of this concentrate are $2.05 \%$ and $1.74 \%$, respectively. However, distribution of

Table 1. Result of Desliming Operation in a 2-Inch Hydrocyclone

\begin{tabular}{|c|c|c|c|c|}
\hline Product & $\mathbf{W t} \%$ & $\mathbf{F e} \%$ & $\mathbf{S i O}_{\mathbf{2}} \%$ & $\mathbf{A l}_{\mathbf{2}} \mathbf{O}_{\mathbf{3}} \%$ \\
\hline \hline Feed & 100 & 54.43 & 9.27 & 8.02 \\
\hline$>150 \mu \mathrm{m}$ size & 80.4 & 58.45 & 6.76 & 5.78 \\
\hline$<150 \mu \mathrm{m}$ size & 19.6 & 37.94 & 19.56 & 17.19 \\
\hline
\end{tabular}

Table 2. Analysis of the Crusher Products

\begin{tabular}{|c|c|c|c|c|c|}
\hline Product & Fe\% & $\mathbf{S i O}_{2} \%$ & $\mathbf{A l}_{\mathbf{2}} \mathbf{O}_{\mathbf{3}} \%$ & Wt\% (wrto*) & Wt\% \\
\hline \hline Feed & 58.45 & 6.76 & 5.78 & 80.4 & 53.7 \\
\hline$-3200+595 \mu \mathrm{m}$ & 58.95 & 6.69 & 5.74 & 26.7 & 66.8 \\
\hline$-595 \mu \mathrm{m}$ & 57.45 & 6.91 & 5.86 & 33.2 \\
\hline
\end{tabular}

*with respect to original. 
Table 3. Jigging Test Results

\begin{tabular}{|c|c|c|c|c|c|}
\hline & Wt\% (wrto*) & Wt\% & $\mathbf{F e \%}$ & $\mathbf{S i O}_{2} \%$ & 6.69 \\
\hline \hline Feed & 53.7 & 100 & 58.95 & 5.11 & 5.74 \\
\hline Jigg Concentrate & 43.9 & 81.8 & 61.12 & 13.78 & 4.24 \\
\hline Jigg tail & 9.8 & 18.2 & 49.23 & 12.48 \\
\hline
\end{tabular}

*with respect to original.

Table 4. Chemical Analysis of the Overall Concentrate After Jigging

\begin{tabular}{|c|c|c|c|c|c|}
\hline Product & $\mathbf{F e} \%$ & $\mathbf{S i O}_{\mathbf{2}} \%$ & $\mathbf{A l}_{\mathbf{2}} \mathbf{O}_{\mathbf{3}} \%$ & Wt\% (wrto*) & Wt\% \\
\hline \hline Combine Product & 59.73 & 5.79 & 4.85 & 70.5 & 100 \\
\hline Jigging Conc. & 61.12 & 5.11 & 4.24 & 43.9 & 62.2 \\
\hline$-0.595 \mathrm{~mm}$ fraction & 57.45 & 6.91 & 5.86 & 26.6 & 37.8 \\
\hline
\end{tabular}

*with respect to original.

Table 5. Tabling Result of the Iron Ore

\begin{tabular}{|c|c|c|c|c|c|}
\hline Product & Wt\% & $\mathrm{Fe} \%$ & $\mathrm{SiO}_{2} \%$ & $\mathrm{Al}_{2} \mathrm{O}_{3} \%$ & Fe Distribution \\
\hline Feed & 70.5 & 59.73 & 5.79 & 4.85 & 100 \\
\hline \multicolumn{6}{|c|}{ Tabling of 300 micron ground feed } \\
\hline Tabling concentrate & 50.4 & 63.76 & 4.12 & 3.65 & 53.80 \\
\hline Tabling middling & 30.43 & 59.97 & 5.78 & 4.51 & 30.55 \\
\hline Tabling tailing & 19.2 & 48.68 & 10.16 & 8.55 & 15.65 \\
\hline \multicolumn{6}{|c|}{ Tabling of 250 micron ground feed } \\
\hline Tabling concentrate & 56.4 & 64.12 & 3.86 & 3.02 & 60.55 \\
\hline Tabling middling & 21.9 & 58.73 & 6.68 & 5.98 & 21.53 \\
\hline Tabling tailing & 21.7 & 49.35 & 9.93 & 8.48 & 17.93 \\
\hline \multicolumn{6}{|c|}{ Tabling of 150 micron ground feed } \\
\hline Tabling concentrate & 52.8 & 65.71 & 2.05 & 1.74 & 58.09 \\
\hline Tabling middling & 14.5 & 55.09 & 9.37 & 8.11 & 13.37 \\
\hline Tabling tailing & 32.7 & 52.12 & 10.24 & 8.42 & 28.53 \\
\hline
\end{tabular}

iron in the concentrate decreased as the feed size decreased to $150 \mu \mathrm{m}$ (Table 5). While weight percentage of particles coarser than $15 \mu \mathrm{m}$ remained relatively high in the concentrate, it dropped for particles less than $15 \mu \mathrm{m}$ (Fig. 8).

To see the efficacy of separation by multigravity separator and to recover the iron loss, the $-150 \mu \mathrm{m}$ ground feed was treated separately in Multi Gravity Separator. A series of batch tests was run in order to determine the optimum operational parameters for the maximum concentrate grade and iron recovery. The drum speed, tilt angle and amount of wash water were adjusted and the MGS was operated. The experimental condition and result are shown in Table 6. Optimum condition is obtained at rotational speed 160 rev/min, tilt angle 4 degree and wash water 3 litre $/ \mathrm{min}$, where the iron grade has been improved to $66.50 \%$ with decreasing the Alumina and Silica to $1.17 \%$ and $1.81 \%$ respectively. Relatively higher grade is obtained in experiment no. 18; however, Fe recovery is relatively low.

\section{DISCUSSION}

Theoretically, effective gravity separation is possible when the concentration criterion [43] for these ores is greater than 2.5 (Equation 1).

$$
\frac{D_{h}-D_{f}}{D_{l}-D_{f}}>2.5
$$

Where, $D_{h}$ is the specific gravity of the heavy mineral, $D_{l}$ is the specific gravity of the light mineral and $D_{f}$ is the specific gravity of the fluid medium. 


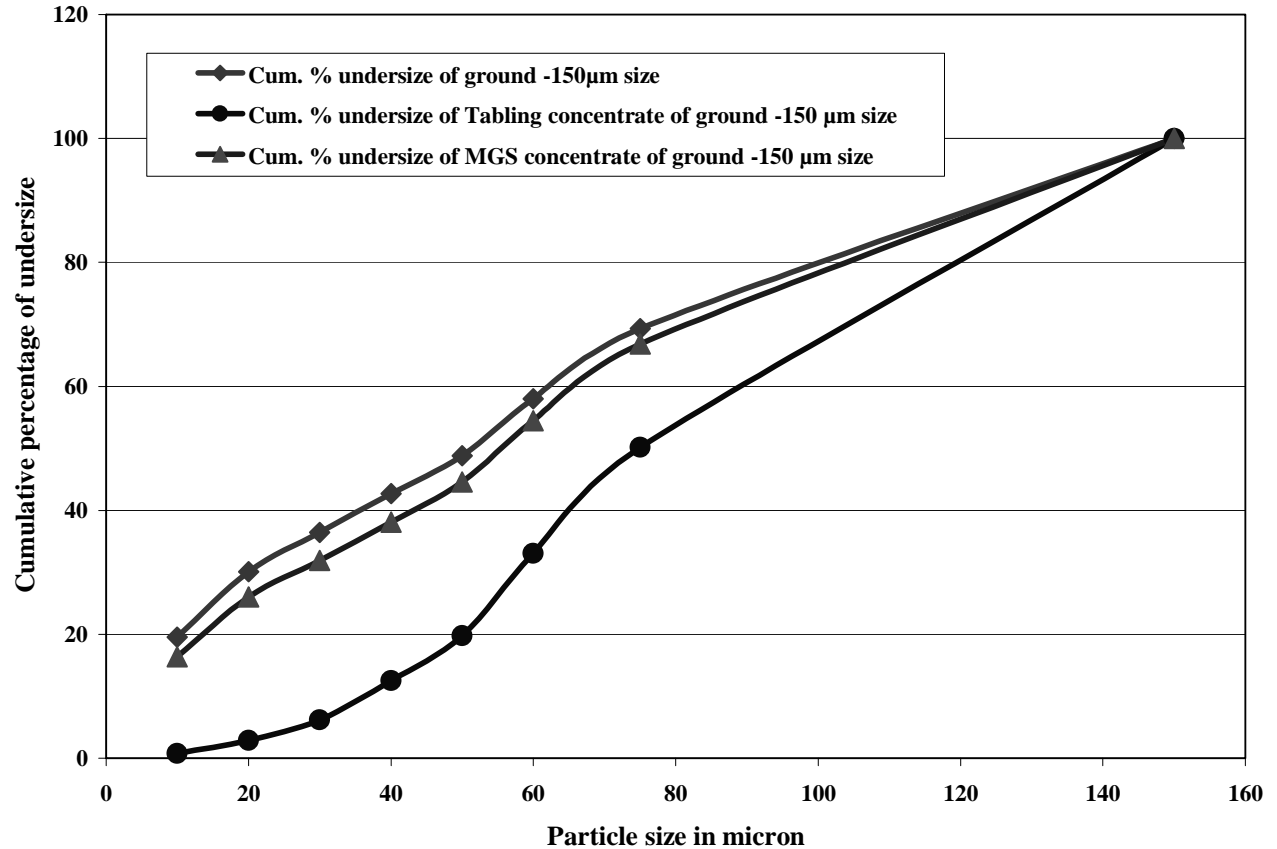

Fig. (8). Graphical representation of particle size distribution of $-150 \mu \mathrm{m}$ ground feed, Tabling concentrate of $-150 \mu \mathrm{m}$ ground feed and MGS concentrate of $-150 \mu \mathrm{m}$ ground feed.

Table 6. MGS Result of -150 $\mu \mathrm{m}$ Size Ground Feed Under Different Condition

\begin{tabular}{|c|c|c|c|c|c|c|c|c|c|c|c|c|c|}
\hline $\begin{array}{l}\text { Expt. } \\
\text { No. }\end{array}$ & $\begin{array}{c}\text { Slope } \\
\text { (Degree) }\end{array}$ & $\begin{array}{c}\text { Water } \\
\text { (litre/min) }\end{array}$ & $\underset{(\mathrm{rev} / \mathrm{min})}{\text { Speed }}$ & \multicolumn{5}{|c|}{ Concentrate } & \multicolumn{5}{|c|}{ Tailing } \\
\hline 2 & 3 & 2 & 200 & 73.24 & 64.80 & 3.88 & 3.31 & 79.46 & 26.76 & 45.87 & 7.50 & 12.58 & 20.55 \\
\hline 5 & 3 & 3 & 200 & 71.64 & 65.17 & 2.66 & 2.96 & 78.16 & 28.36 & 45.99 & 10.39 & 12.95 & 21.84 \\
\hline 6 & 3 & 3 & 240 & 68.54 & 65.87 & 3.32 & 3.11 & 75.59 & 31.46 & 46.35 & 8.18 & 11.62 & 24.41 \\
\hline 7 & 3 & 4 & 160 & 71.24 & 64.82 & 2.60 & 2.68 & 77.31 & 28.76 & 47.18 & 10.44 & 13.50 & 22.72 \\
\hline 11 & 4 & 2 & 200 & 68.34 & 65.57 & 2.32 & 1.92 & 75.02 & 31.66 & 47.13 & 10.32 & 14.13 & 24.98 \\
\hline 12 & 4 & 2 & 240 & 65.24 & 66.12 & 1.18 & 1.76 & 72.22 & 34.76 & 47.74 & 11.74 & 13.36 & 27.78 \\
\hline 13 & 4 & 3 & 160 & 67.64 & 65.47 & 2.26 & 2.80 & 74.14 & 32.36 & 47.72 & 10.26 & 12.05 & 25.85 \\
\hline 14 & 4 & 3 & 200 & 65.44 & 65.73 & 2.20 & 2.23 & 72.01 & 34.56 & 48.37 & 9.87 & 12.54 & 27.99 \\
\hline 15 & 4 & 3 & 240 & 63.34 & 66.50 & 1.17 & 1.81 & 70.52 & 36.66 & 48.02 & 11.21 & 12.68 & 29.47 \\
\hline 16 & 4 & 4 & 160 & 66.34 & 65.87 & 1.19 & 1.86 & 73.16 & 33.66 & 47.63 & 12.06 & 13.54 & 26.84 \\
\hline 17 & 4 & 4 & 200 & 64.44 & 66.32 & 1.18 & 1.50 & 71.55 & 35.56 & 47.80 & 11.50 & 13.57 & 28.46 \\
\hline
\end{tabular}


When the quotient is greater than 2.5 , then gravity separation is relatively easy. As the value of quotient decreases, so the efficiency of separation decreases, and below about 1.25 gravity separation is not commercially feasible [43]. The specific gravity of hematite is 5.5 to 6.5 whereas it is 4.1 to 4.3 in case of goethite. Specific gravity of kaolinite, gibbsite and quartz is in the range from 2.3 to 2.6. In case of hematite ore, separation criterion as shown in Eqn. (1), is estimated to be in the range from 2.81 to 3.44 . On the other hand, separation criterion in case of goethite ore is estimated to be in the range from 1.93 to 2.06 . Therefore, the more goethitic the ore, the lower is the efficiency of separation. This leads to a greater percentage of the $\mathrm{Fe}$ going to the tailing during gravity separation. In the present work high percentage of $28.53 \% \mathrm{Fe}$ distribution in tailing product for ore during Tabling of $-150 \mu \mathrm{m}$ (Table 5) is due to high concentration of goethitic ore in the feed which makes the concentration criterion lower than 2.5. This effect can also seen in Jigging result, where high percentage of $\mathrm{Fe}$ distribution (15.24\%) has been obtained in tailing product.

Distribution of $\mathrm{Fe}$ in the tailing product of Tabling is lower in $-250 \mu \mathrm{m}$ ground ore sample than $-300 \mu \mathrm{m}$, however, in $-150 \mu \mathrm{m}$ ground feed it increases sharply (Table 5). Liberation analysis (Fig. 5) shows that with decreasing the particle size from $350 \mu \mathrm{m}$ to $150 \mu \mathrm{m}$, more iron bearing minerals are liberated. So liberated iron minerals should report to the concentrate product rather than to tailings. The loss of $\mathrm{Fe}$ in tailing can be demonstrated by following theoretical considerations.

The equation of downstream travel, before a particle at the top of fluid film settles at the deck surface [17] is given as,

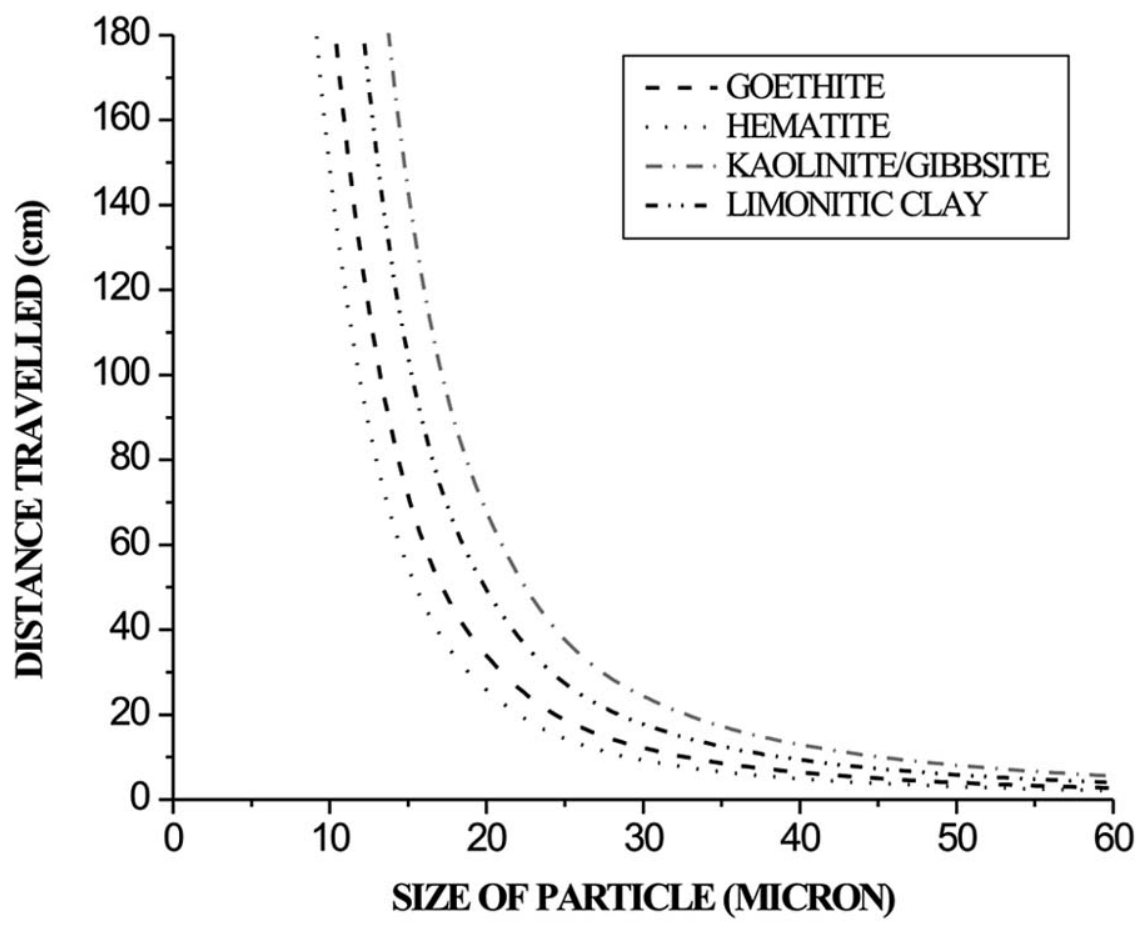

Fig. (9). Graphical representation of down stream travel of all types of particle.

$$
z=\frac{9}{2} \frac{\mu Q}{(D s-D f) r g \cos \alpha}
$$

In this equation, $\mathrm{z}$ is the downstream travel expressed in $\mathrm{cm}, \mathrm{Q}$ the rate of fluid flow in cubic centimeters per centimeter of running deck length per second, $\mu$ the viscosity $(\mathrm{g} / \mathrm{cm} / \mathrm{s}), \mathrm{r}$ the particle radius $(\mathrm{cm}), \mathrm{g}$ is the acceleration due to gravity $\left(\mathrm{cm} / \mathrm{s}^{2}\right)$, Ds and Df the specific gravities of solid and fluid $\left(\mathrm{g} / \mathrm{cm}^{3}\right)$ and $\alpha$ is the slope of the deck. The particle radius appears in the denominator raised to the second power.

Graphical representation of down stream travel of all types of particle is represented in Fig. (9) as estimated from Equation (2). The permissible distance is taken as 60 $\mathrm{cm}$ which is the length across the Shaking Table. As seen from Fig. (9), the maximum size of particle of hematite and goethite traveling $60 \mathrm{~cm}$ or more are 11 micron and 13 micron respectively. The ore particles below these size limits are invariable lost in the tailings. Loss of fine sized goethite is relatively higher than fine hematite.

In present study grinding of ores to $-150 \mu \mathrm{m}$ causes formation of undesirable amount of fines below $15 \mathrm{~m} \mu$. Size distribution of $-150 \mu \mathrm{m}$ ground ores is given in the Fig. (8). Due to high content of goethite in the ore it produced significant amount of fines and significant amount of $\mathrm{Fe}$ is lost in this ore type. It can be seen from Table 5, the distribution of $\mathrm{Fe}$ in tailings product of $-150 \mu \mathrm{m}$ ground feed is $17.86 \%$.

Size distribution (Fig. 8) shows that below $20 \mu \mathrm{m}$ significant amount of fines $(30.1 \%)$ are generated during grinding of the ore. The heavy liquid separation result reveals (Table 7) that this size fraction contains $21.27 \%$ of heavies. Tabling concentrate $-20 \mu \mathrm{m}$ sized fraction contains only $2.83 \%$ 
Table 7. Sink Float Test Result of $\mathbf{- 1 5 0} \mu \mathrm{m}$ Size Ground Feed, Tabling Concentrate of $\mathbf{- 1 5 0} \mu \mathrm{m}$ Size Ground Sample and MGS Concentrate of $\mathbf{- 1 5 0} \mu \mathrm{m}$ Size Ground Sample

\begin{tabular}{|c|c|c|c|c|c|c|}
\hline \multirow[t]{2}{*}{ Size in Micron } & \multicolumn{2}{|c|}{ Ground $150 \mu \mathrm{m}$ Size Feed } & \multicolumn{2}{|c|}{ Tabling Concentrate of Ground $150 \mu \mathrm{m}$ Size } & \multicolumn{2}{|c|}{ MGS Concentrate of Ground $150 \mu \mathrm{m}$ Size } \\
\hline & Wt $\%$ & Sink \% & Wt $\%$ & Sink \% & Wt $\%$ & Sink \% \\
\hline$-150+75$ & 30.67 & 24.12 & 49.86 & 49.25 & 33.21 & 33.11 \\
\hline$-75+60$ & 11.32 & 8.13 & 17.15 & 16.94 & 12.33 & 12.23 \\
\hline$-60+50$ & 9.21 & 7.78 & 13.23 & 12.82 & 9.89 & 9.78 \\
\hline$-50+40$ & 6.13 & 5.24 & 7.26 & 7.2 & 6.45 & 6.45 \\
\hline$-40+30$ & 6.23 & 5.16 & 6.36 & 6.19 & 6.23 & 6.11 \\
\hline$-30+20$ & 6.31 & 4.78 & 3.33 & 3.18 & 5.89 & 5.78 \\
\hline$-20+10$ & 10.56 & 6.44 & 2.11 & 1.34 & 9.64 & 9.45 \\
\hline-10 & 19.57 & 14.83 & 0.72 & 0.53 & 16.36 & 16.12 \\
\hline Total & 100.00 & 76.48 & 100.0 & 97.45 & 100.00 & 99.03 \\
\hline
\end{tabular}

of heavies, indicating significant amount of heavies (iron particles) is lost during the processing. Additionally, the limonitic clay also plays important role in the loss of Fe in the tailings product since limonitic clay contains significant amount of Fe. As shown in the Fig. (9), downstream travel of this particle is $17 \mu \mathrm{m}$. Large amount of limonitic clay is removed by this effect.

Although the grade of Tabling concentrate for $-150 \mu \mathrm{m}$ sized feed is acceptable, the Fe loss is substantial. Therefore, it is imperative to process the ore using advanced gravity separation techniques such as MGS. The MGS process improved the Fe from $54.43 \%$ to $66.5 \%$ along decreasing the silica and alumina to $1.81 \%$ and $1.17 \%$ respectively. The improvement in the $\mathrm{Fe}$ recovery in the form of sink product can be seen in Table 7. In comparison with the conventional gravity separation by Wilfley Table where Fe recovery is $58.09 \%$, this has been improved to $70.52 \%$ by MGS process. Detail discussion of the effect of MGS variable on responses such as grade, yield and iron recovery is presented below.

\section{Effect of Drum Speed}

The rotational speed of the drum is the most important operational parameter. In the experiments, the drum speed was varied between $160 \mathrm{rev} / \mathrm{min}$ and $240 \mathrm{rev} / \mathrm{min}$. The iron grade is increase from $65.87 \%$ to $66.51 \%$ by decreasing drum rotation from $240 \mathrm{rev} / \mathrm{min}$ to $160 \mathrm{rev} / \mathrm{min}$ (Table 6). Similar trend is observed in all combinations of drum rotation. Table shows that good recoveries could be obtained at higher drum speeds. However, at higher drum speeds grade of the concentrate is diluted due to recovery of unwanted minerals. At higher drum rotations higher centrifugal forces are generated on heavier and fine iron particles along with coarse lighter particles (i.e. low value hydrated iron particles). Thereby increasing the recovery of iron and decreasing the grade. These fine particles compact bed is difficult to be influenced by wash water effects or drum inclination. It can be observed from result that lower drum speed coupled with higher wash water and degree of slope gave much cleaner product. The drum rotation is found to have more influenced on iron recovery in comparison to wash water and drum inclination.

\section{Effect of Wash Water}

An increase in wash water from 2 to 4 litre/min has increased the iron grade in all combinations of other variables. For instance, an increase in wash water from 3 to 4 litre/min, keeping drum inclination and drum rotation constant at 4 and $240 \mathrm{rev} / \mathrm{min}$ respectively there is an increase in iron grade from $65.47 \%$ to $65.87 \%$. The similar observation is made in all other combinations of variables. Table $\mathbf{6}$ depicts the effect of wash water on recovery of iron values. It can be observed that an increase in wash water decreases the recovery of iron values irrespective of drum speed and angle of slope. It may be due to the fact that increase in volume of water increases the forward flow of water which carries the fine iron particles to the tailing stream causing the reduction in recovery.

\section{Effect of Drum Inclination}

The drum inclinations studied in the present test work are 3 and 4 degrees (Table 6). An increase in drum inclination from lower level to higher level, causes an improvement in iron grade. An increase of drum inclination from 3 to 4 degrees keeping wash water and drum rotation constant at 2 litre/min and $240 \mathrm{rev} / \mathrm{min}$ respectively, causes an increase in iron grade from $64.32 \%$ to $65.13 \%$. The similar trend observed in all other combinations of variables. It can be shown from the Table that the recovery is decreased by increasing angle of slope at all levels of drum speed and wash water, which may be due to more mobility of particles in the bed at higher slope.

\section{CONCLUSIONS}

Beneficiation studies indicate that gravity separation by Wilfley Table is not very effective for the processing of low grade iron ore fines. The nature of minerals in the ore plays important role in the separation process. Hematitic ores are handled more efficiently in gravity separation by Jigging and Wilfley Table than goethitic ores since the concentration criteria of hematite is higher than that of goethite. Due to friable nature of ore, it produces large quantity of fines during comminution. Thus, the concentration efficiency of this 
ore is poorer. Also, downstream travel of fines is more prominent in goethite than in hematite. Therefore, concentration of ore is more problematic as fines are lost in tailings more significantly. Multi Gravity Separator has been used in place of Wilfley Table and was found to be effective in reducing loss of fine iron particles and increasing the grade of the concentrate. The experimental result on MGS indicated that a recovery of $70.52 \%$ iron can be maintained with $66.50 \%$ iron grade. Among the MGS variable studied, drum rotation has the more significant effect on iron grade followed by wash water and drum inclination.

\section{ACKNOWLEDGEMENT}

Financial assistance in the form of CSIR fellowship to authors is gratefully acknowledged. The author thanks the editor and the three reviewers for their comments which significantly improved the manuscript.

\section{REFERENCES}

[1] S. Roy, A. Das, and M. K. Mohanty, "Feasibility to producing pellet grade concentrate by beneficiation of iron ore slimes in India", Separation Science and Technology, vol. 42, pp. 32713287, 2007

[2] S. Roy, and A. Das, "Characterization and processing of low grade iron ore slime from Jilling area of India", Mineral Processing and Extractive Metallurgy Review, vol. 29, pp. 213-231, 2008

[3] S. Roy, A. Das, and A. S. Venkatesh, "A comparative mineralogical and geochemical characterisation of iron ores from two Indian Precambrian deposits and Krivoy rog deposit, Ukraine: implications for the upgrading of lean grade ore", Applied Earth Science: IMM Transactions Section B, vol. 117 (23), pp. 125-147, 2008

[4] R. K. Upadhyay, and A. S. Venkatesh, "Current strategies and future challenges on exploration, beneficiation and value addition of iron ore resources with special emphasis on iron ores from eastern India", Applied Earth Science IMM Transactions Section B, vol. 115, pp. 187-195, 2006

[5] B. Das, S. Prakash, B. K. Mohapatra, S. K. Bhaumik, and K. S. Narasimhan, "Beneficiation of iron ore slimes using hydrocyclone", Mineral and Metallurgical Processing, vol. 9, pp. 101-103, 1992.

[6] B. Gujraj, J. P. Sharma, A. Baldawa, S. C. D. Arora, N. Prasad, and A. K. Biswas, "Dispersion-flocculation studies on hematite-clay systems", International Journal of Mineral Processing, vol. 11, pp. 285-302, 1983.

[7] K. H. Rao, and K. S. Narasimhan, "Selective flocculation applied to Barsuan iron ore tailings", International Journal of Mineral Processing, vol. 14, pp. 67-75, 1985.

[8] S. Mahiuddin, S. Bandopadhyay, and J. N. Baruah, "A study on the beneficiation of Indian iron ore fines and slime using chemical additives", International Journal of Mineral Processing, vol. 11, pp. 285-302, 1989.

[9] N. Prasad, M. A. Ponomarev, S. K. Mukherjee, P. K. Sengupta, P. K. Roy and S. K. Gupta, "Introduction of new technologies for beneficiation of Indian hematite ores, reduction of losses and increase in their quality", in XVI International Mineral Processing Congress, Forssberg, 1988, pp.1369-1380.

[10] Pradip, "Beneficiation of alumina-rich Indian iron-ore slimes", Metals Materials and Processes, vol. 6, pp. 179-194, 1995.

[11] B. Das, B. K. Mohapatra, P. S. R. Reddy, and S. Das, "Characterization and beneficiation of iron ore slimes for further processing", Powder Handling and Process, vol. 7, pp. 41-44, 1995.

[12] M. P. Srivastava, S. K. Pan, N. Prasad, and B. K. Mishra, "Characterization and processing of iron ore fines of Kiriburu deposit of India", International Journal of Mineral Processing, vol. 61, pp. 93-107, 2001.

[13] R. Burt, "The role of gravity concentration in modern processing plants", Minerals Engineering, vol. 12, pp. 1291-1300, 1999.

[14] P. A. Olubambi, and J. H. Potgieter, "Effectiveness of gravity concentration for the beneficiation of itakpe (Nigeria) iron ore achieved through jigging operation", Journal of Minerals \& Materials Characterization and Engineering, vol. 4, pp. 21-30, 2005.
[15] A. K. Mukherjee, D. Bhattacharjee, and B. K. Mishra, "Role of water velocity for efficient jigging of iron ore", Minerals Engineering, vol.19, pp. 952-959, 2006.

[16] R. A. Bagnold, "Experiments on gravity free dispersion of large solid spheres in a Newtonian fluid under share", Proceedings Royal Society Series, vol. 225, pp. 49-53, 1954.

[17] A. M. Gaudin, Principles of Mineral Dressing. New Delhi, Tata McGraw-Hill Publishing Company Limited, Mohan Makhijani at Rekha Printers Pvt. Ltd, 1987.

[18] R. J. Mansar, R.W. Barley, and B. A. Wills, "The shaking Table concentrator- The influence of operating conditions and table parameters on mineral separation - The development of a mathematical model for normal operating conditions", Mineral Engineering, vol. 4, pp. 369-381, 1991.

[19] C. Mills, The theory of gravity separation. Gravity Separation Technology. Short Course, University of Nevada, Preprint, 1978.

[20] R. Shivamohan, and E. Forssberg, "Principles of tabling", International Journal of Mineral Processing, vol.15, pp. 281-295, 1985.

[21] E. Samykina, A. Surkov, L. Eppelbaum, and S. Semenov, "Do old spoils contain large amounts of economic minerals?", Minerals Engineering, vol. 18, pp. 643-645, 2005.

[22] J. Svoboda, and V. E. Ross, "Particle capture in the matrix of a magnetic separator", International Journal of Mineral Processing, vol. 27, pp. 75-94, 1989.

[23] J. Svoboda, "The effect of magnetic field strength on the efficiency of magnetic separation”, Mineral Engineering, vol. 7, pp. 747-757, 1994.

[24] V. V. Karmazin, M. A. Bikbov, and A. A. Bikbov, " The energy saving technology of beneficiation of iron Ore", Magnetic and Electrical Separation, vol. 11(4), pp. 211-224, 2002.

[25] J. Svoboda, and T. Fujita, "Recent developments in magnetic methods of material separation", Mineral Engineering, vol. 16, pp. 785-793, 2003.

[26] S. Song, S. Lu, and A. Lopez-Valdivieso, "Magnetic separation of hematite and limonite fines as hydrophobic flocs from iron ores", Mineral Engineering, vol. 15, pp. 415-422, 2002.

[27] A. I. Arol, and A. Aydogan, "Recovery enhancement of magnetite fines in magnetic separation", Colloids Surface A: Physicochemistry Engineering Aspects, vol. 232, pp. 151-154, 2004.

[28] S. Sysila, H. Laapas, K. Heiskanen, and E. Ruokonen, "The effect of surface potential on the flotation of chromite", Minerals Engineering, vol. 9(5), pp. 519-525, 1996.

[29] K. B. Quast, "A Review of hematite flotation using 12- Carbon chain collectors", Mineral Engineering, vol. 13, pp. 1361-1376, 2000.

[30] A. Surkov, E. Samykina, L. Eppelbaum, and S. Semenov, "The main reason for mineral loss in gravity dressing", The Open Mineral Processing Journal, vol .1, pp. 37-44, 2008.

[31] L. Chen, N. Ren, and D. Xiong, "Experimental study on performance of a continuous centrifugal concentrator in reconcentrating fine hematite", International Journal of Mineral Processing, vol. 87, pp. 9-16, 2008.

[32] K. P. Calvin, A. Callen, D. Zhou, and E. Doroodchi, "Performance of the reflux classifier for gravity separation at full scale", Minerals Engineering, vol. 18, pp. 19-24, 2005.

[33] R.G. Richards, and M.K. Palmer, "High capacity gravity separators a review of current status", Minerals Engineering, vol. 10, pp. 973982, 1997.

[34] B. S. K. Chan, R. H. Mozley, and G. J. C. Chids, "Extended trials with the high tonnage multi gravity separator", Mineral Engineering, vol. 4, pp. 489-496, 1991.

[35] J. W. G. Turner, and M.P. Hallewell, "Process improvements for fine cassiterite recovery at Wheal Jane", Mineral Engineering, vol. 6, pp. 817- 829, 1993.

[36] R.O. Burt, G. Kornik, S. R.Young, and C. Deveay, "Ultrafine tantalum recovery strategies", Mineral Engineering, vol. 8, pp. 859-870, 1995.

[37] T. Cicek, and I. Cocen, "Applicability of Mozley multigravity separator (MGS) to fine chromite tailings of Turkish chromite concentrating plants", Minerals Engineering, vol. 15, pp. 91-93., 2002.

[38] S. Owada, and T. Harada, "Mineralogical properties and fundamental mineral processing behaviour of the chromite contained in laterite leach residue", International Journal of Mineral Processing, vol. 19, pp. 77-97, 1987. 
[39] N. Aslan, "Multi-objective optimization of some process parameters of a multi-gravity separator for chromite concentration", Separation and Purification Technology, vol. 64, pp. 237-241, 2008.

[40] B. S. K. Chan, R.H. Mozley, and G.T.C. Childs, "The Multigravity separator (MGS),- A mine scale machine", in Mineral Processing in the United Kingdom, London, P.A. Dowd Ed., London: IIM Publishers., 1989, p.107.
[41] P. Tucker, "Modelling the multi-gravity separator", in XVII International Mineral Processing Congress, Dresden, Germany, 1991, p.77.

[42] C. Klein, C.S. Hurlbut.; Jr. Manual of mineralogy. $20^{\text {th }}$ ed., New York: John Wiley and Sons, 1985.

[43] B. A. Wills, Mineral Processing Technology. $4^{\text {th }}$ ed, Headington Hil Hall, Oxford, England: Pergamon Press, 1988.

(C) Subrata Roy; Licensee Bentham Open.

This is an open access article licensed under the terms of the Creative Commons Attribution Non-Commercial License (http://creativecommons.org/licenses/by$\mathrm{nc} / 3.0 /$ ) which permits unrestricted, non-commercial use, distribution and reproduction in any medium, provided the work is properly cited. 